The Microphone for Military and Tonometric Purposes

MY attention lias just been called to a paper on the micro phone, by Prof. W. F. Barrett, in NATURE (vol. xix. p. 12), in which it is asked whether the latter " has ever been tried by military men to detect the mining operations of an enemy?" Will you ailow me to state that this application of the microphone suggested itself to me many months ago, and that I have begun to make experiments both in this direction and also with a view to ascertain to what extent sounds can be transmitted to a microphone immersed in water. Unfortunately the pressure of other matters has hindered me from completing the work, which, however, I hope shortly to be able to do.

May I take this opportunity of saying that I have been endea. vouring with some success to apply the principle of the micro phone to the counting of the beats of two slightly dissonan tuning-forks. In one experiment the two forks were inverted and screwed through a board above which the ends of their stems protruded. A thin piece of carbon was laid over these ends and the arrangement was placed in circuit with a Bell telephone. The beats were loudly heard and continued audible long after their direct sound had ceased. A reflecting galvanometer being placed in the circuit the beats were shown by deflections of the light spot, but irregularities in the current made it difficult to count them satisfactorily. The forks were then screwed horizontally into a vertical board and a screw was inserted about I" from the stem of each and on the same horizontal level. A small piece of carbon was laid over each stem and its adjacent screw. This plan gave even better results, and admits of the forlis being any reasonable distance apart. The experiments were tried with two forks whose vibration numbers were about 60 , and also with a pair of octave forks with vibration numbers of about 256 and $5 \mathrm{r2}$. A small piece of copper wire was then attached to each of the two large forks, and mercury cups were so placed that the points of the wires were just not touching the place surface when the forks were at rest. Both mercury cups were connected to one pole of the battery, and the current was arrauged to branch through the forks uniting at the telephone. The beats were very loud. This plan, however, involves difficuities on account of the delicacy of adjustinent required for the mercury surfaces and also the amalgamation of the copperpoints. Several other experiments have been tried, but the method first described seems worth a trial by those interested in tonometry. The counting of beats, which is not an easy matter for aged or unaccustomed ears, may thus be immensely facilitated, while the period of the forks under observation is absolutely unaffected. The carbon used was that employed for the electric light, and it is probable that more carefully prepared and homogeneous material would have given better results in a galvano. ineter experiment.

Cooper's Hill, November 19

\section{The Microphone as a Receiver}

ON the 3 rd of June last, in a paper read before the Royal Society of Edinburgh, I described an experiment which showed that the microphone could be used, not only as a transmitter, but also as a receiver of articulate sounds. An abstract of the but also as a receiver or after in NATURE, and since then I have paper appearications from several experimenters, stating that they had failed to repeat the experiment, and asking for some details regarding it. I trust, therefore, that you will kindly give me space for a short explanation.

In performing the experiment the transmitting and receiving iustruments which I used were precisely identical. Each was merely an ordinary white pcrcelain jam-pot, $3 \frac{1}{2}$ inches in diameter and 4 inches deep, half filled with gas:coke, broken into coarse fragments and provided with electrodes whereby a current of electricity could be sent through the pieces of coke. Cinders from ordinary coal, if well burned, would, of course, do equally well. The electrodes were two strips of tin about two inches wide slipped down, opposite to each other, between the cinders and the sides of the jam-pot and fastened by being bent over the the sides and bound round the outside with a cord. When these edges and bound round the puir of ordinary telephones, jam-pots were put in circuit like a pair of ordinary telephones, and a battery of two strong Grove's cells, was complete.

included in the circuit the arrangement was no difficulty in making myself and

In this way I lave had no difficulty in making myself and otliers clearly hear the articulation is not so dis tinct as I have no doubt it will be when proper forms both of transmitter and receiver are adopted.

I may mention that since then I have found the result to be greatly improved by including a stronger battery in the circuit. Edinburgh, November 18 JAMES BLYTH

\section{Wind-Pressure}

I BECAME acquainted, some years since, with the singularly great wind-pressures registered at the Liverpool Observatory, and $I$ should be rather disposed to attribute them to the exceptional position of the wind-gauge than to think (as the writer of an article in NATURE, vol. xix. p. 25, appears to do) that the gauge is erroneous. I do not remember to have seen it noticed, in the recent discussions on the Cleopalra's Needle, that there is probably a rapid increase of wind-pressure from the ground-surface upwards. In any river the velocity is least at the bottom, and near the bottom the change is rapid. Similarly, in the great current formed by the wind, I imagine there is a much less velocity near the ground than at some distance above it, and less on a plain than above a hill standing out of the plain. Now I believe the Bidstone Observatory is on a bill, with the great plain formed by the Atlantic in front of it. It is, therefore, in a position in which it receives an exceptionally heavy wind-pressure. The pressure on the wind-gauge is pro bably much greater than on the windows of the observatory, and that, again, is probably greater than the pressure on buildings more inland, where the current near the ground has been more interfered with by obstructions. On the other hand, Cleopatra's Needle is in a very protected position, where I should be much surprised to find that the wind-pressure ever reached even 40 lbs. per square foot.

As Mr. Dixon has referred to the case of a window to dis. prove the possibility of a pressure of $80 \mathrm{lbs}$. per square foot, it may be well to see whether it is really conclusive. I have not at liand any formula for the resistance of a simply-supported square plate, but it will not be vexy different from that of a circular plate. Now, let $p=$ pressure per square inch on surface of plate, $t$ its thickness, 1 its radius. Then the greatest stress in the plate is by Grashof's formula, $f=\frac{5}{6} \cdot \frac{r^{2}}{t^{2}} p$. Taking a plate of glass 2 feet diameler, $\frac{1}{8}$ inch thick, and loaded with 80 lbs. per square foot, we get $f=4,270$ lbs. per square inch. In some experiments which I made under Sir W. Fairbairn's direction, the tenacity of glass was found to be from 4,200 to 6,000 lbs. per square in. Hence, surprising as it may seem, it is probable that a pane of glass 2 feet diameter would sustain a load of 80 lbs, per square foot, uniformly distributed, without breaking, or a load equivalent to that of a dense crowd of people. I don't, of course, think that a window would be safe if subjected to such a pressure, but it is always desirable to subject general statements of this kind to exact calculation; and I think we may at least infer that well-constructed glass windows would sustain a considerable wind-pressure without necessarily giving way.

Cooper's Hill, November i'7

\section{Was Homer Colour-blind ?}

I CRAVE some little space for a few remarks with regard to the recently much vexed question as to the traditional blindness of Homer.

It seems to have been overlooked that, apart from the statement made by Herodotus ${ }^{\mathrm{t}}$ (in his life of Homer), that in

I Homer, according to Herodotus, was born about 167 years after the Trojan war and, when still a child, adopted by his stepfather, to whom he succeeded in the management of a school. At an early age, however, it would seem, he set out for distant voyages and, at length, after having spent some time on visiting Tyrrhenia and Iberia, when about 32 or 34 years of age, lost his siont from what appears to have been some chronic disease of the eyes. Previously, when at Ithaca, he is said already to have had a narrow escape from that calamity. The text of this important narrative runs thus :-

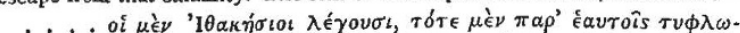

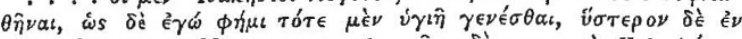

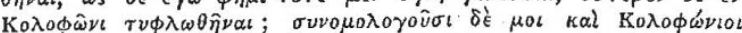

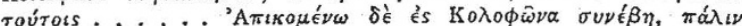

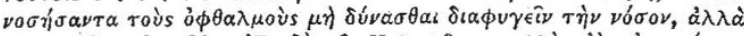

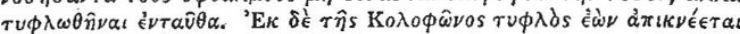
$\epsilon i s \tau \eta \dot{\nu} \nu \Sigma_{\mu} \dot{\omega} \rho \nu \alpha . . .$.

Frum Colophon he sailed to Sinyrna, where, for his sustenance, he began and, afterwards, continued, during his long wanderings, and for a good many years, the recital of his verses. 